\title{
Role of Vitamin D in Colorectal Cancer: A Holistic Approach and Review of the Clinical Utility
}

Moiz Javed ${ }^{1}$, Aldanah Althwanay ${ }^{1}$, Farah Ahsan ${ }^{1}$, Federico Oliveri ${ }^{2}$, Harshit K. Goud ${ }^{3}$, Zainab Mehkari ${ }^{4}$ , Lubna Mohammed ${ }^{1}$, Ian H. Rutkofsky ${ }^{5}$

1. Internal Medicine, California Institute of Behavioral Neurosciences \& Psychology, Fairfield, USA 2. Cardiology, California Institute of Behavioral Neurosciences \& Psychology, Fairfield, USA 3. Medicine, California Institute of Behavioral Neurosciences \& Psychology, Fairfield, USA 4. Internal Medicine, California Institute of Behavioral Neuroscience \& Psychology, Fairfield, USA 5. Psychiatry, California Institute of Behavioral Neurosciences \& Psychology, Fairfield, USA

Corresponding author: Moiz Javed, moizjaved100@gmail.com

\begin{abstract}
Vitamin D is well known for its effects on the homeostasis of calcium and phosphorus. Lately, considerable research has brought the extra-skeletal role of vitamin D under the spotlight, including its anti-cancer activity. Colorectal cancer (CRC) is the most extensively studied neoplasia that has been observed to be affected by vitamin D; the list includes breast, prostate, and ovarian cancer. This review aims to shine a light on the influence of vitamin D over CRC and to further understand its ability to be used as a potential economical treatment for CRC patients. For this review, PubMed was used as the main database for the literature search. Studies on the role of vitamin D on CRC within 10 years and all of the study types were included. Post the extensive research over PubMed, it was noted that vitamin D, through its effect on multiple pathways, especially Wnt/ $\beta$-catenin, apoptosis, and inflammation, hinders the progression of CRC carcinogenesis. High levels of this steroid hormone can delay the progression and may provide a costeffective way of treating CRC patients. Further research and additional human trials are still due to bring about more knowledge on this topic. In conclusion, high serum levels of vitamin D are associated with a lower risk of incidence and progression of CRC.
\end{abstract}

Received 08/12/2020 Review began 08/28/2020 Review ended 09/28/2020 Published 09/30/2020

\section{(c) Copyright 2020} Javed et al. This is an open access article distributed under the terms of the Creative Commons Attribution License CC-BY 4.0., which permits unrestricted use, distribution, and reproduction in any medium, provided the original author and source are credited.
Categories: Endocrinology/Diabetes/Metabolism, Gastroenterology, Oncology

Keywords: colon cancer, vitamin d, $1 \alpha, 25$-dihydroxyvitamin d3

\section{Introduction And Background}

Colorectal cancer (CRC) is the third most common and the second most lethal cancer worldwide. In 2018, 1.8 million new cases and 881,000 deaths were reported for CRC, which accounted for almost $10 \%$ of new cancer cases and deaths worldwide [1]. It is projected that there will be nearly 2.5 million new cases by the year 2035 [2]. The initial genetic changes begin in an early adenoma that is initially transformed from the normal colorectal epithelium. Multiple pathways like the chromosomal instability, microsatellite instability, and CpG island methylator phenotype pathways are responsible for the adenoma's conversion to carcinoma [3]. MLH1, MSH2, MSH6, PMS2, BMPR1A, MSAD4, POLE, NTHL1, MUTYH, POLD1 and adenomatous polyposis coli (APC) are some well-researched germ-line mutations recognized to increase the susceptibility of CRC [4]. So far there hasn't been a therapy designed that could treat each of the CRCs as one since they all have different driving mutations. Surgery remains to be the leading treatment early on in the disease course but as seen in $25 \%$ of the diagnoses when cancer has metastasized, surgery is no longer curative [5]. In patients with stage III CRC, adjuvant chemotherapy with cytotoxic agents plays a critical role as the standard of care [6]. Recent case-controlled studies have displayed an inverse correlation between serum levels of vitamin D and the incidence of human CRC and multiple studies proposed lower incidence of colon cancer, polyp recurrence, and overall survival for patients with colon cancer with higher vitamin D3 levels [7].

Vitamin D is known for its role in regulating bone metabolism primarily through calcium absorption from the intestines and bone remodeling [8]. Endogenous exposure to ultraviolet B radiation stands as the major source of vitamin D for most of the people, which then converts 7-dehydrocholesterol in the skin to vitamin D, later hydroxylated to 25 -hydroxyvitamin D, i.e. 25(OH)D, a secosteroid hormone. 25(OH)D is converted to 1,25-dihydroxyvitamin D, i.e. $1,25(\mathrm{OH}) 2 \mathrm{D}$, the most active metabolite of vitamin $\mathrm{D}$ by enzyme $1-\alpha-$ hydroxylase. Vitamin $D$ is also noted to engage in a variety of physiological pathways including regulation of cell cycle, cellular proliferation, angiogenesis, apoptosis, and molecular cell signaling. This validates its participation in tumorigenic activity [9]. 1,25D3 binds to a specific vitamin D receptor (VDR), which is a member of the nuclear receptor superfamily. VDR then binds to retinoid X receptor (RXR), and the VDR-RXR heterodimers bind to a vitamin $\mathrm{D}$ response element (VDRE), which then controls the activation or repression of gene expression [7]. Higher serum levels of vitamin D have been shown to be protective against metastasis in patients with stage IV melanoma. Breast, ovarian, pancreatic, and prostate cancer patients have also benefited from the chemopreventive activities of vitamin D [7]. The literature has supported the relationship in various studies. The overexpression of VDR has been found in CRC and was linked to the phosphatidylinositol 3-kinase (PI3K)-AKT pathway and KRAS mutations [10]. VDR polymorphisms, which 
include Taql, Bsml, Tru91, have also shown to be possible risk factors for CRC [4]. In this article, our aim is to review the literature concerning vitamin D and CRC mortality, present-day guidelines in regard to vitamin D supplementation, and to address the gaps in the research.

\section{Review}

\section{Method}

The main databases used for searching relevant publications were PubMed and Google Scholar. By using the keywords colon cancer, colorectal cancer, vitamin D, 1 $\alpha, 25$-dihydroxyvitamin D3, and calcitriol, the search was made with no geographical restriction, for articles on vitamin D and its role in colon cancer. Medical Subject Headings (MeSH) keywords colonic neoplasms and vitamin D was also used for the search. Results yielded were 54,081 peer-reviewed published articles listed for colon cancer, 40,175 peer-reviewed published articles listed for vitamin D, 850 peer-reviewed published articles listed for $1 \alpha, 25$-dihydroxyvitamin D3, 322 peer-reviewed published articles listed for combined keywords vitamin D and colon cancer, 607 peerreviewed published articles listed for combined keywords vitamin D and colorectal cancer, and 154 peerreviewed published articles listed for combined keywords calcitriol and colorectal cancer. The search results that were yielded are summarized in Table 1 . No restriction of study type, including systemic reviews, investigation of clinical trials, and meta-analysis, was applied in the review. No selection was based on age, gender, and ethnicity. Studies older than 10 years from July 2020 were excluded.

\begin{tabular}{|c|c|c|}
\hline Keyword & Database & Number of results \\
\hline Colon cancer & PubMed & 54,081 \\
\hline Vitamin D & PubMed & 40,175 \\
\hline 1a,25-dihydroxyvitamin D3 & PubMed & 850 \\
\hline Vitamin D and colon cancer & PubMed & 322 \\
\hline Vitamin D and colorectal cancer & PubMed & 607 \\
\hline Calcitriol and colorectal cancer & PubMed & 154 \\
\hline
\end{tabular}

TABLE 1: Search results for the keywords and combinations from PubMed

\section{Discussion}

Proposed Pathways Involving Vitamin D and CRC

Several potential pathways have been suggested in the involvement of vitamin D in CRC, including its role in apoptosis, initiation of differentiation in colonic epithelium, and suppression of angiogenesis. Mutation in the APC tumor suppressor gene is the primary genetic change in the majority of colorectal adenomas, which is a primary step in the development of CRC. To a smaller extent, AXIN2 and CTNNB1/ $\beta$-catenin genes are also involved. Additionally, activating mutation in the KRAS and BRAF, and an inactivating mutation in the transforming growth factor (TGF)- $\beta$ pathway plays a role in the malignancy of adenoma cells [11].

According to recent studies, the up-regulation of expression of the calcium-sensing receptor (CaSR), an important player in cell proliferation, has been proposed in the list of antineoplastic effects of vitamin D [12]. CaSR interacts with the cell cycle of colonocytes via inhibition of the $\beta$-catenin/T-cell factor (TCF) transcription complex, promoting E-cadherin activation and lowering the concentration of 25hydroxyvitamin D 24-hydroxylase (CYP24A1) [13]. A study conducted by Aggarwal et al., in which in vivo mice were fed with a high vitamin D diet, showed a notably higher amount of CaSR expression, decreased quantity of colonic proliferating cells, and unregulated apoptosis [14]. Wnt signaling pathway is an established contributor to the progression of CRC [15]. The accelerated growth of the tumor and malignancy were contributed to the hyperactive Wnt/ $\beta$-catenin pathway after the loss of VDR. As compared to healthy colon cells, there was a notable increase in the colonic Wnt and $\beta$-catenin stained cells in colorectal and colitis patients, with an increase of 4.5 folds and 2.5 folds, respectively [16]. 1,25D suppresses $\beta$-catenin transcriptional activity. Independently without the involvement of the VDR DNA binding site, 1,25D suppresses the transcriptional activity of $\beta$-catenin and expression of the $\beta$-catenin target gene DDK- 4 . In the presence of APC, a tumor suppressor, which represses the Wnt pathway, the activity of 1,25D against $\beta$ catenin is enhanced [7]. Larriba et al. supported the direct relation between nuclear $\beta$-catenin levels and VDR functions in controlling the activity of Wnt/ $\beta$-catenin signaling in colon cancer. The effects were shown both in vivo and vitro with the help of Apcmin/+Vdr-/- mice and cultured human colon cancer cells in which shRNA was used to knock down the expression of VDR. The study reported induction of the expression of E- 
cadherin and antagonization of the Wnt/ $\beta$-catenin pathway to enhance epithelial differentiation and inhibition of proliferation of human colon cancer cells by 1,25(OH)2D3 [17]. Figure 1 illustrates these effects. $\mathrm{E}$-cadherin is an integral protein involved in epithelial cell adhesion. Its loss results in the conversion of a more invasive phenotype of an epithelial cell from its normal phenotype. E-cadherin for that reason is considered as a proto-oncogene [18]. Furthermore, secreted frizzled-related protein 2 (SFRP2) is an inhibitor of Wnt and its prompted CpGs have been documented to methylate at a high rate in CRCs [19]. Vitamin D decreases the promoter methylation of SFRP2, which then antagonizes Wnt, which could help in the ability of vitamin D to work with neoadjuvant treatments and improve their response in patients with CRC [20].

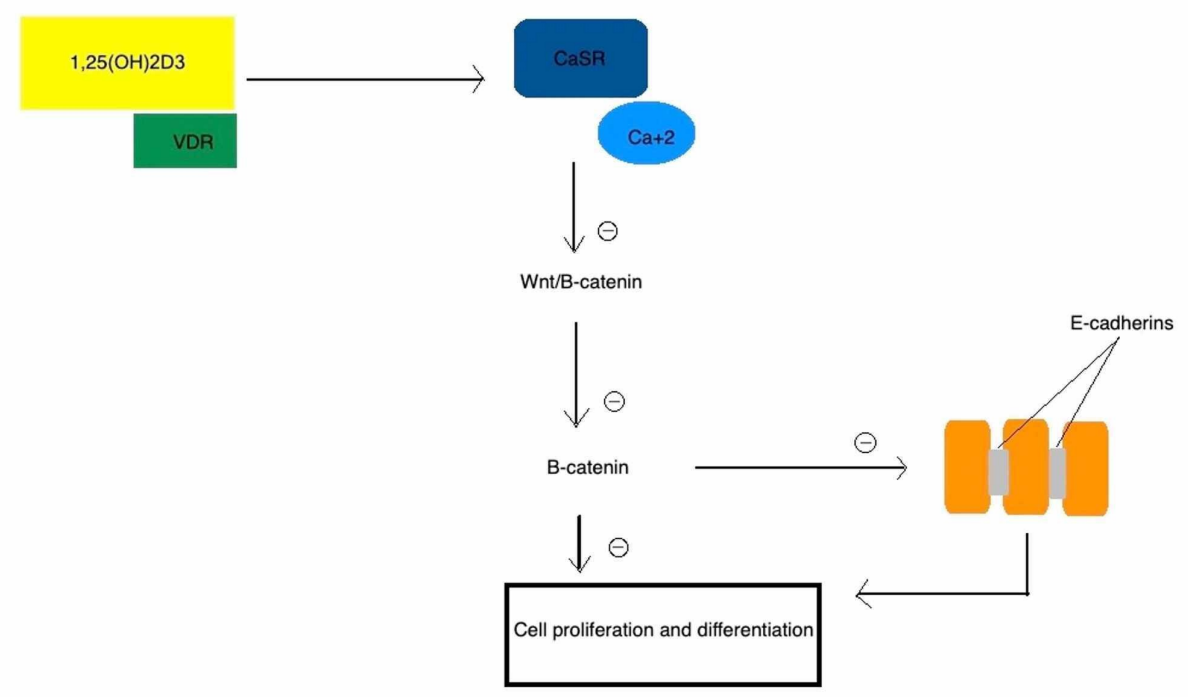

\section{FIGURE 1: Vitamin D and its effects on the Wnt/ß-catenin pathway and} E-cadherins

VDR: vitamin D receptor

Vitamin D also affects the process of apoptosis in CRC cells. Apoptosis is programmed cell death, a process through which all the multicellular organisms go through [21]. These cells go through characteristic changes in their morphology as a part of the process of apoptosis, these include blebbing, fragmentation of the nucleus, shrinkage of the cell, condensation of the chromatin, and fragmentation of the chromosomal DNA [22]. 1,25(OH)2D3 in colorectal adenomas and carcinoma causes the downregulation of BAG1, an antiapoptotic protein in the nucleus, and the up-regulation of a proapoptotic protein BAK1. It also causes an increase in the expression of G0S2, which is a mitochondrial protein that interacts with Bcl-2 to induce apoptosis in CRC cells by preventing the formation of anti-apoptotic heterodimers between Bcl-2 and BAX [11]. Colonic epithelial VDR inhibits apoptosis in the epithelium by downregulating p53 upregulated modulator of apoptosis (PUMA), an important proapoptotic regulator that protects the mucosal barrier of the colon and reduces inflammation [23]. Moreover, various inflammatory pathways that take part in the progression of CRC such as the nuclear factor (NF)-KB and cyclooxygenase pathways, and many cytokines, such as tumor necrosis factor (TNF)- $\alpha$, interleukin (IL)-1 $\beta$, IL-6, IL-8, IL-17, and TGF- $\beta 1$, have shown to be affected by vitamin D. CRC patients have higher serum levels of these cytokines. A randomized, doubleblind, placebo-controlled, 2 × 2 factorial trial by van Harten-Gerritsen et al. studied patients with colorectal adenoma, which were given 800 international units of vitamin D3 and/or $2 \mathrm{~g}$ calcium versus placebo for over six months. Although not statistically significant, post-six-month baseline measurements of plasma inflammatory markers and serum vitamin D displayed high levels of vitamin D with decreased levels of CRP, TNF- $\alpha$, IL-1 $\beta$, IL-6, and IL-8 in the group that received vitamin D. The group that received the calcium and vitamin D had decreased levels of IL-1 $\beta$, IL-6, and IL-8 [24].

\section{Serum Levels of Vitamin D and Risk of CRC}

The association between mortality in CRC patients and lower vitamin D levels resulting from weak ultraviolet-B radiations at high altitudes was first put forward by Garland and Garland in 1980 [25]. Since then, many studies have supported this relationship. Most of the patients who were newly diagnosed with CRC were found to have either deficient or insufficient levels of 25(OH)D [26]. Studies have also suggested restoring the level of $25(\mathrm{OH}) \mathrm{D}$ to normal levels of $30-80 \mathrm{ng} / \mathrm{mL}$ in CRC patients who are deficient and regularly monitoring its level [27]. In Intergroup Trial N9741, Ng et al. concluded that stage IV CRC patients who were receiving chemotherapy as first-line treatment, particularly female and Black patients, had a high 
prevalence of vitamin D deficiency. With levels $\geqslant 30 \mathrm{ng} / \mathrm{mL}$ of $25(\mathrm{OH}) \mathrm{D}$ levels considered as sufficient, 25(OH)D levels lower than $20 \mathrm{ng} / \mathrm{mL}$ were defined as vitamin D deficiency, and 20-29 ng/mL were regarded as insufficiency. In the study, $82 \%$ of the study population were vitamin D insufficient and $50 \%$ were deficient in vitamin D [28].

A nested case-control study by Chandler et al. included 274 female CRC cases and 274 female controls and followed the study population for 16.3 years to find out that those with $25(\mathrm{OH}) \mathrm{D}$ levels above $29 \mathrm{ng} / \mathrm{mL}$ were seen to have the highest reduction in the incidence and mortality with CRC [29]. The serum level of vitamin D and its effect on CRC-related mortality have also been highlighted by the dose-response analysis involving 17,700 participants from 18 studies by Wu et al. The study found a $12 \%$ lower risk of colorectal-specific mortality and a $7 \%$ reduction in the risk of all-cause mortality with an increase of every $20 \mathrm{nmol} / \mathrm{L}$ of 25(OH)D [30]. Moreover, data from 17 cohorts, including 5706 CRC patients and 7107 control participants, were used in a study by McCullough et al. and showed that the most favorable concentration of 25(OH)D for risk reduction of CRC was $75-100 \mathrm{nmol} / \mathrm{L}$, which is higher than the current Institute of Medicine (IOM) recommendations. The study also highlighted that the higher levels of circulating 25(OH)D had a statistically significant effect on women and a non-statistically significant effect on men for lowering the risk of CRC [31]. The reduced risk of CRC with vitamin D serum levels in male and female patients from diverse ethnic groups such as African American, Latino, White, Native Hawaiian, and Japanese has also been observed [32]. To further explore the effects in different races, another meta-analysis with CRC patients in Asian countries was conducted by Zhang et al. that showed a statistically significant reduction in the risk of CRC by $21 \%$ for every $16 \mathrm{ng} / \mathrm{mL}$ increase in serum vitamin D levels with an odds ratio (OR) of 0.79 (95\% CI 0.64 to 0.97 ) [33]. However, low-dose vitamin D supplementation of $400 \mathrm{IU}$ per day did not benefit in the reduction of CRC risk as shown by Women's Health Initiative (WHI), a randomized placebo-controlled trial [34].

\section{Vitamin D as a Potential Treatment in CRC}

The overall survival of patients with CRC is directly related to higher circulating levels of 25(OH)D. With this reduction in the all-cause and CRC-specific mortality, 25(OH)D can be an excellent protective agent that could positively affect the prognosis in these patients [30]. 25(OH)D-derived analogs have been developed to provide more potent antineoplastic effects and counter the unwanted calcemic side effects that have been a problem with using 25(OH)D alone as a treatment for cancer [35]. PRI-2191, a vitamin D analog, increases the expression of E-cadherin and arrests the cells in the G0/G1 cell cycle phase. It is noted to work alongside 5-fluorouracil (5-FU), the oldest drug used to treat CRC, in enhancing and extending its anticancer effects in in vivo mice. PRI-2191 can be used in the colon cancer treatment regimen to increase the effects of 5-FU [36]. SUNSHINE, a double-blinded, multicenter, phase II randomized clinical trial with untreated 139 colorectal patients gave one group of study participants $400 \mathrm{IU}$ of vitamin D per day and the other group 4,000 IU vitamin D per day. Both groups also received standard chemotherapy. The results showed a median delay time of 13 months for the worsening of disease progression in those receiving the high-dose vitamin $\mathrm{D}$ and 11 months in the low-dose vitamin D group. Furthermore, those in the high-dose group had a 36\% less chance of CRC progression or death during the follow-up time of 22.9 months [37]. However, adding 2,000 IU of cholecalciferol per day into the standard chemotherapy regimen of metastatic cancer patients for two years in another study did not produce any advantages in the overall survival or the progression-free survival with a follow-up period of 46 months [38]. With the results from many preclinical and clinical studies, the inverse relationship between vitamin D deficiency and the risk of developing CRC has been advocated. Vitamin D addition can be an economical and secure way of reducing the incidence and improving prognosis in CRC despite the variable support from the existing early studies. More randomized control trials in humans are warranted to solidify the relationship [39].

Table 2 shows the studies used in the review and their relevant findings. 


\section{Cureus}

\begin{tabular}{|c|c|c|c|c|}
\hline Author & $\begin{array}{l}\text { Year of } \\
\text { publication }\end{array}$ & $\begin{array}{l}\text { Study } \\
\text { design/type } \\
\text { of study }\end{array}$ & Topic & Findings \\
\hline $\begin{array}{l}\text { Ng et al. } \\
{[28]}\end{array}$ & 2011 & $\begin{array}{l}\text { Intergroup } \\
\text { trial N9741 }\end{array}$ & $\begin{array}{l}\text { Vitamin D status in patients with stage IV } \\
\text { CRC }\end{array}$ & $\begin{array}{l}\text { Stage IV CRC patients had a high prevalence of } \\
\text { vitamin D deficiency. }\end{array}$ \\
\hline $\begin{array}{l}\text { Larriba et } \\
\text { al. [17] }\end{array}$ & 2011 & $\begin{array}{l}\text { Animal } \\
\text { model colon } \\
\text { cancer APC } \\
\text { min/+ mice }\end{array}$ & $\begin{array}{l}\text { VDR deficiency enhances Wnt/ } \beta \text {-catenin } \\
\text { signaling and tumor burden in colon } \\
\text { cancer. }\end{array}$ & $\begin{array}{l}\text { VDR is a key participant of the } W n t / \beta \text {-catenin } \\
\text { pathway in controlling tumor growth in CRC. }\end{array}$ \\
\hline $\begin{array}{l}\text { Pereira et } \\
\text { al. [11] }\end{array}$ & 2012 & Review & Vitamin D and colon cancer & $\begin{array}{l}\text { Vitamin D has a protective role against CRC } \\
\text { especially in the prevention. }\end{array}$ \\
\hline $\begin{array}{l}\text { Milczarek et } \\
\text { al. [36] }\end{array}$ & 2013 & $\begin{array}{l}\text { In vivo } \\
\text { mouse } \\
\text { model }\end{array}$ & $\begin{array}{l}\text { Vitamin } D \text { analogs enhance the } \\
\text { anticancer activity of } 5 \text {-FU in an in vivo } \\
\text { mouse colon cancer model. }\end{array}$ & $\begin{array}{l}\text { With vitamin D analogs PRI- } 2191 \text { and PRI- } \\
2205 \text {, the activity of } 5 \text {-FU was appreciably } \\
\text { increased with a decreased growth of the } \\
\text { tumor, metastasis, and increased survival in } \\
\text { the mice. }\end{array}$ \\
\hline Klampfer [7] & 2014 & Review & Vitamin D and colon cancer & $\begin{array}{l}\text { Calcitriol through its interaction with VDR } \\
\text { inhibits Wnt signaling pathway and exerts its } \\
\text { anticancer effects. }\end{array}$ \\
\hline $\begin{array}{l}\text { van Harten- } \\
\text { Gerritsen et } \\
\text { al. [24] }\end{array}$ & 2015 & Review & $\begin{array}{l}\text { Vitamin D, inflammation, and CRC } \\
\text { progression }\end{array}$ & $\begin{array}{l}\text { Vitamin D controls cytokines, TNF-a, IL-1 } 13 \text {, IL- } \\
6 \text {, IL-8, IL-17, and TGF- } \beta 1 \text { and COX2 and NF- } \\
\text { KB pathways in CRC. }\end{array}$ \\
\hline $\begin{array}{l}\text { Ng et al. } \\
{[37]}\end{array}$ & 2019 & $\begin{array}{l}\text { Randomized } \\
\text { clinical trial }\end{array}$ & $\begin{array}{l}\text { vitamin D3 supplementation on } \\
\text { progression-free survival among } \\
\text { patients with advanced or metastatic } \\
\text { colorectal cancer }\end{array}$ & $\begin{array}{l}\text { Increased progression-free survival in CRC } \\
\text { patients from } 11 \text { to } 13 \text { months when high-dose } \\
\text { vitamin D used with chemotherapy vs } \\
\text { chemotherapy alone }\end{array}$ \\
\hline $\begin{array}{l}\text { McCullough } \\
\text { et al. [31] }\end{array}$ & 2019 & $\begin{array}{l}\text { International } \\
\text { pooling } \\
\text { project of } 17 \\
\text { cohorts }\end{array}$ & Circulating vitamin $\mathrm{D}$ and $\mathrm{CRC}$ risk & $\begin{array}{l}75-100 \mathrm{nmol} / \mathrm{L} \text { of } 25(\mathrm{OH}) \mathrm{D} \text { is optimal for } \\
\text { reducing } \mathrm{CRC} \text { risk in women and men. }\end{array}$ \\
\hline
\end{tabular}

\section{TABLE 2: Studies included in this review with their pertinent findings}

25(OH)D: 25-hydroxycholecalciferol; APC: adenomatous polyposis coli; CRC: colorectal cancer; COX2: cyclooxygenase-2; 5-FU: 5-fluorouracil; IL: interleukin; NF-kB: nuclear factor-kB; TNF-a: tumor necrosis factor-a; TGF- $\beta 1$ : transforming growth factor- $\beta 1$; VDR: vitamin D receptor

\section{Limitations}

Most of the studies included are animal studies done on mice. Some of the human studies had a limited number of participants involved. There is a need for further extensive human trials to get more insight into the effects of vitamin D on colon cancer for it to be included in the treatment plan for the prevention of high-risk patients and those with diagnosed colon cancer.

\section{Conclusions}

1,25D3 after binding to its receptor, VDR, exerts its anti-neoplastic effects by changing the expression of multiple genes. Vitamin D has a pro-apoptotic and anti-inflammatory effect, in addition to its inhibition of the Wnt/ $\beta$-catenin, to decrease the growth and differentiation of colon epithelial cells. Studies suggest the increase in the incidence of CRC with low serum levels of vitamin D. Higher levels of vitamin D have been suggested to prevent CRC and to decrease the mortality in CRC patients; meanwhile, the addition of lowlevel vitamin D did not show significant results. The ability of vitamin D analogs to work alongside the already established CRC treatments, like 5-FU, would provide an economical additional treatment for such patients. However, additional large-scale human trials are warranted to further investigate this relationship to clearly devise a more systematic treatment plan that includes vitamin D.

\section{Additional Information \\ Disclosures}


Conflicts of interest: In compliance with the ICMJE uniform disclosure form, all authors declare the following: Payment/services info: All authors have declared that no financial support was received from any organization for the submitted work. Financial relationships: All authors have declared that they have no financial relationships at present or within the previous three years with any organizations that might have an interest in the submitted work. Other relationships: All authors have declared that there are no other relationships or activities that could appear to have influenced the submitted work.

\section{References}

1. Bray F, Ferlay J, Soerjomataram I, Siegel RL, Torre LA, Jemal A: Global cancer statistics 2018: GLOBOCAN estimates of incidence and mortality worldwide for 36 cancers in 185 countries. CA Cancer J Clin. 2018, 68:394-424. 10.3322/caac.21492

2. Xie YH, Chen YX, Fang JY: Comprehensive review of targeted therapy for colorectal cancer. Signal Transduct Target Ther. 2020, 5:22. 10.1038/s41392-020-0116-Z

3. Armaghany T, Wilson JD, Chu Q, Mills G: Genetic alterations in colorectal cancer. Gastrointest Cancer Res. 2012, 5:19-27.

4. Sheng S, Chen Y, Shen Z: Correlation between polymorphism of vitamin D receptor TaqI and susceptibility to colorectal cancer: a meta-analysis. Medicine (Baltimore). 2017, 96:e7242. 10.1097/MD.0000000000007242

5. Rawla P, Sunkara T, Barsouk A: Epidemiology of colorectal cancer: incidence, mortality, survival, and risk factors. Prz Gastroenterol. 2019, 14:89-103. 10.5114/pg.2018.81072

6. Gustavsson B, Carlsson G, Machover D, et al.: A review of the evolution of systemic chemotherapy in the management of colorectal cancer. Clin Colorectal Cancer. 2015, 14:1-10. 10.1016/j.clcc.2014.11.002

7. Klampfer L: Vitamin D and colon cancer. World J Gastrointest Oncol. 2014, 6:430-437. 10.4251/wjgo.v6.i11.430

8. Meeker S, Seamons A, Maggio-Price L, Paik J: Protective links between vitamin D, inflammatory bowel disease and colon cancer. World J Gastroenterol. 2016, 22:933-948. 10.3748/wjg.v22.i3.933

9. Mahendra A, Karishma, Choudhury BK, Sharma T, Bansal N, Bansal R, Gupta S: Vitamin D and gastrointestinal cancer. J Lab Physicians. 2018, 10:1-5. 10.4103/JLP.JLP_49_17

10. Hargrove L, Francis T, Francis H: Vitamin D and GI cancers: shedding some light on dark diseases . Ann Transl Med. 2014, 2:1-9. 10.3978/j.issn.2305-5839.2013.03.04

11. Pereira F, Larriba MJ, Muoz A: Vitamin D and colon cancer. Endocr Relat Cancer. 2012, 19:R51-R71. 10.1530/ERC-11-0388

12. Morales-Oyarvide V, Meyerhardt JA, Ng K: Vitamin D and physical activity in patients with colorectal cancer: epidemiological evidence and therapeutic implications. Cancer J. 2016, 22:223-231. 10.1097/PPO.0000000000000197

13. Ahearn TU, McCullough ML, Flanders WD, et al.: A randomized clinical trial of the effects of supplemental calcium and vitamin D3 on markers of their metabolism in normal mucosa of colorectal adenoma patients. Cancer Res. 2011, 71:413-423. 10.1158/0008-5472.CAN-10-1560

14. Aggarwal A, Höbaus J, Tennakoon S, et al.: Active vitamin D potentiates the anti-neoplastic effects of calcium in the colon: a cross talk through the calcium-sensing receptor. J Steroid Biochem Mol Biol. 2016, 155:231-238. 10.1016/j.jsbmb.2015.02.006

15. Welsh J: Cellular and molecular effects of vitamin D on carcinogenesis . Arch Biochem Biophys. 2012, 523:107-114. 10.1016/j.abb.2011.10.019

16. Garcia PM, Moore J, Kahan D, Hong MY: Effects of vitamin D supplementation on inflammation, colonic cell kinetics, and microbiota in colitis: a review. Molecules. 2020, 25:2300. 10.3390/molecules25102300

17. Larriba MJ, Ordóñez-Morán P, Chicote I, Martín-Fernández G, Puig I, Muñoz A, Pálmer HG: Vitamin D receptor deficiency enhances Wnt/ $\beta$-catenin signaling and tumor burden in colon cancer. PloS One. 2011, 6:e23524. 10.1371/journal.pone.0023524

18. Stubbins RE, Hakeem A, Núñez NP: Using components of the vitamin D pathway to prevent and treat colon cancer. Nutr Rev. 2012, 70:721-729. 10.1111/j.1753-4887.2012.00522.x

19. Takeda M, Nagasaka T, Dong-Sheng S, et al.: Expansion of CpG methylation in the SFRP2 promoter region during colorectal tumorigenesis. Acta Med Okayama. 2011, 65:169-177. 10.18926/amo/46628

20. Boughanem H, Cabrera-Mulero A, Hernández-Alonso P, et al.: Association between variation of circulating 25-OH vitamin D and methylation of secreted frizzled-related protein 2 in colorectal cancer. Clin Epigenetics. 2020, 12:83. 10.1186/s13148-020-00875-9

21. Ye ZS, Fan LN, Wang L, et al.: Immunoglobulin E induces colon cancer cell apoptosis via enhancing cyp27b1 expression. Am J Transl Res. 2016, 8:5715-5722.

22. Adamiec-Mroczek J, Zając-Pytrus H, Misiuk-Hojło M: Caspase-dependent apoptosis of retinal ganglion cells during the development of diabetic retinopathy. Adv Clin Exp Med. 2015, 24:531-535. 10.17219/acem/31805

23. Liu W, Chen Y, Golan MA, et al.: Intestinal epithelial vitamin D receptor signaling inhibits experimental colitis. J Clin Invest. 2013, 123:3983-3996. 10.1172/JCI65842

24. van Harten-Gerritsen AS, Balvers MG, Witkamp RF, Kampman E, van Duijnhoven FJ: Vitamin D, inflammation, and colorectal cancer progression: a review of mechanistic studies and future directions for epidemiological studies. Cancer Epidemiol Biomarkers Prev. 2015, 24:1820-1828. 10.1158/1055-9965.epi-150601

25. Hou N, Huo D, Dignam JJ: Prevention of colorectal cancer and dietary management. Chin Clin Oncol. 2013, 2:13. 10.3978/j.issn.2304-3865.2013.04.03

26. Savoie MB, Paciorek A, Zhang L, et al.: Vitamin D levels in patients with colorectal cancer before and after treatment initiation. J Gastrointest Cancer. 2019, 50:769-779. 10.1007/s12029-018-0147-7

27. Mohr SB, Gorham ED, Kim J, Hofflich H, Cuomo RE, Garland CF: Could vitamin D sufficiency improve the survival of colorectal cancer patients?. J Steroid Biochem Mol Biol. 2015, 148:239-244.

10.1016/j.jsbmb.2014.12.010

28. Ng K, Sargent DJ, Goldberg RM, et al.: Vitamin D status in patients with stage IV colorectal cancer: findings 


\section{Cureus}

from Intergroup trial N9741. J Clin Oncol. 2011, 29:1599-1606. 10.1200//CO.2010.31.7255

29. Chandler PD, Buring JE, Manson JE, et al.: Circulating vitamin D levels and risk of colorectal cancer in women. Cancer Prev Res (Phila). 2015, 8:675-682. 10.1158/1940-6207.CAPR-14-0470

30. Wu G, Xue M, Zhao Y, et al.: Low circulating 25-hydroxyvitamin D level is associated with increased colorectal cancer mortality: a systematic review and dose-response meta-analysis. Biosci Rep. 2020, 40:BSR20201008. 10.1042/BSR20201008

31. McCullough ML, Zoltick ES, Weinstein SJ, et al.: Circulating vitamin D and colorectal cancer risk: an international pooling project of 17 cohorts. J Natl Cancer Inst. 2019, 111:158-169. 10.1093/jnci/djy087

32. Woolcott CG, Wilkens LR, Nomura AM, et al.: Plasma 25-hydroxyvitamin D levels and the risk of colorectal cancer: the multiethnic cohort study. Cancer Epidemiol Biomarkers Prev. 2010, 19:130-134. 10.1158/10559965.EPI-09-0475

33. Zhang L, Zou H, Zhao Y, et al.: Association between blood circulating vitamin D and colorectal cancer risk in Asian countries: a systematic review and dose-response meta-analysis. BMJ Open. 2019, 9:e030513. 10.1136/bmjopen-2019-030513

34. Ng K: Vitamin D for prevention and treatment of colorectal cancer: what is the evidence? . Curr Colorectal Cancer Rep. 2014, 10:339-345. 10.1007/s11888-014-0238-1

35. Leyssens C, Verlinden L, Verstuyf A: Antineoplastic effects of 1,25(OH)2D3 and its analogs in breast, prostate and colorectal cancer. Endocr Relat Cancer. 2013, 20:R31-R47. 10.1530/ERC-12-0381

36. Milczarek M, Psurski M, Kutner A, Wietrzyk J: Vitamin D analogs enhance the anticancer activity of 5fluorouracil in an in vivomouse colon cancer model. BMC Cancer. 2013, 13:294. 10.1186/1471-2407-13-294

37. Ng K, Nimeiri HS, McCleary NJ, et al.: Effect of high-dose vs standard-dose vitamin D3 supplementation on progression-free survival among patients with advanced or metastatic colorectal cancer: the SUNSHINE randomized clinical trial. JAMA. 2019, 321:1370-1379. 10.1001/jama.2019.2402

38. Antunac Golubić Z, Baršić I, Librenjak N, Pleština S: Vitamin D supplementation and survival in metastatic colorectal cancer. Nutr Cancer. 2018, 70:413-417. 10.1080/01635581.2018.1445766

39. Feldman D, Krishnan AV, Swami S, Giovannucci E, Feldman BJ: The role of vitamin D in reducing cancer risk and progression. Nat Rev Cancer. 2014, 14:342-357. 10.1038/nrc3691 